\title{
A Study of the Speech Act of Apologies by Chinese EFL Learners at Different Levels of Grammatical Proficiency
}

\author{
Jiang Qian \\ School of Foreign Languages, Yunnan Normal University, Kunming, Yunnan, P. R. China \\ 1271530736@qq.com
}

\begin{abstract}
Keywords: Communicative competence, Pragmatic competence, Grammatical competence, The speech act of apology.
\end{abstract}

\begin{abstract}
The purpose of this paper is to report on a study examining the developmental pragmatic competence of Chinese learner of English at different levels of grammatical proficiency. Bardovi-Harlig argues that although grammatical competence may not be a sufficient condition for pragmatic development, it may be a necessary condition [10]. The study investigates the relationship between grammatical proficiency levels and the realization of apologies by Chinese learners in Chinese EFL context.The findings suggest that the students' level of grammatical proficiency does have an influence on their performance of the speech act of apology.
\end{abstract}

\section{Introduction}

The introduction of the important concept 'communicative competence' into language acquisition has made many researchers shift their concerns from the isolated, decontextualized linguistic components to pragmatic aspects of language ability [1]. As a components of linguistic competence, pragmatic competence focuses on the effectiveness and appropriateness of language in use. Studies have been done to investigate whether there is a positive or negative correlation between L2 learner's linguistic proficiency and pragmatic competence. This paper aims to investigate the correlation between Chinese English major students' grammatical competence and their L2 pragmatic competence by investigating the similarities and differences between their selections of strategies and semantic formulae in the speech act apologies.

\section{Communicative competence, Linguistic competence and Pragmatic competence}

\subsection{Communicative Competence}

Hymes' notion of communicative competence brings a shift of emphasis from linguistic concern to a growing interest in language use in language ability. According to this notion, language acquisition should not only involve acquiring separate, decontextualized linguistic components, but also involving the knowledge of language in use and it is necessary to relate language to the extralinguistic factors as sociocultural rules and language context. Based on Hymes' original notion of communicative competence, Canale and Swain proposes a framework of the components for communicative competence. In their view, communicative competence includes the following three components: grammatical competence, sociolinguistic competence and strategic competence. Grammatical competence refers to the correct use of lexical items and the knowledge of morphology, syntax, sentence-grammar, and semantics. Strategic competence refers to the use of both verbal and nonverbal repairs to remedy the breakdown caused by the lack of language ability in communication. Sociolinguistic competence refers to the appropriateness of the utterance according to the sociocultural rules and rules of speaking [2]. 


\subsection{Pragmatic competence and Linguistic competence}

Within the perspectives of Canale and Swain's framework of communicative competence, pragmatic concerns are viewed as in part of sociolinguistic competence. Thomas defines pragmatic competence as " the ability to use language effectively in order to achieve a specific purpose and to understand language in context"[3]. When the speaker's meaning is perceived different from what the speaker wants to say by the hearer on any occasion, or there is an inability to recognize the force of an utterance, pragmatic failure will occur. The failure can be either 'sociopragmatic failure' (inability to understand the social standards) or ' pragmalinguistic failure'( inability to use linguistic form appropriately, or producing utterances which convey unintended illocutionary force). Thomas' observation of adults who came to Britain speaking fluent English but never attained a high degree of pragmatic competence confirms the idea that "pragmatic competence can never simply be grafted onto grammatical competence"[3].

\subsection{Interlanguage pragmatics}

Many research have been done to investigate learner's pragmatic competence cross-culturally. "When the investigation focuses more specifically on the communicative behavior of non-native speakers, attempting to communicate in their second language, it is described as interlanguage pragmatics "[4]. Therefore, Interlanguage pragmatics refers to the study of how non-native speakers communicate in a second language. There are a range of factors that will influence learner's interlanguage pragmatic sophistication including transfer, linguistic proficiency, length of exposure, instruction and individual factors [5]. Yates further points out that an interlanguage user who has higher grammatical competence may know how to use a range of structures, but lack the ability in using the language appropriately because of the unawareness of the sociopragmatic norm and culture of the target language [5].

\section{The speech act of apologizing}

\subsection{Definition}

According to Searle, there are five basic kinds of action that one can perform in speaking. They are directives, expressives, representatives, commissives and declarations[6]. Apology is the speech act that belongs to expessives category which indicates the speaker's "psychological state or attitudes"[7]. Therefore, apology is a remedy strategy used after an offense, so it is a typical post-event speech act in which the speaker intends to provide the hearer support after the hearer is offended by an violation[8].

\subsection{Strategy types of apology}

Olshtain and Cohen (1983) classify the speech act set for apologies as showed in Table 1. Blum-Kulka, House, Kasper further points out that the first strategy ( an expression of an apology) is the most explicit one realized by an illocutionary force indicating device (IFID) which uses a formulatic expression of regret such as ' (be) sorry' in English, and thus it is a direct strategy. The other three strategies (an explanation or account of the situation, an acknowledgement of responsibility, and a promise of forbearance) are indirect strategy[9]. 
Table 1: The speech act set for apologies (information and examples taken from Olshtain and Cohen 1983)[10]

\begin{tabular}{|c|c|}
\hline Strategy & Example \\
\hline 1 An expression of an apology & \\
\hline a. expression of an apology & I'm sorry. \\
\hline b. an offer of apology & I apologize. \\
\hline c. a request for forgiveness & Excuse me. \\
\hline $\begin{array}{l}2 \text { An explanation or account of the situation } \\
3 \text { An acknowledgement of responsibility }\end{array}$ & The bus was late. \\
\hline a. accepting blame & It's my fault. \\
\hline b.expressing self-deficiency & I wasn't thinking. \\
\hline $\begin{array}{l}\text { c.recognizing the other person as } \\
\text { deserving apology }\end{array}$ & You are right. \\
\hline d.expressing lack of intent & I didn't mean to. \\
\hline e. an offer of repair & I'll pay for the broken vase. \\
\hline 4 A promise of forbearance & It won't happen again. \\
\hline
\end{tabular}

Speakers will choose different strategy types to perform an apology or choose any combination of the strategies to express an apology according to the seriousness of the offence and use intensifiers to increase the intensity of the illocutionary force of an apology. There are evidence that the learner's level of linguistic proficiency influence how the learner apologize.

\section{The study}

\subsection{Aims of the study}

This paper will analyze the frequency with which apology strategies are used by two groups of students with different grammatical proficiency and it will draw some conclusions about how learner's L2 grammatical competence can affect their performance of an apology.

The study aims to:

1. to identify differences or similarities in the use of apology strategies by students with different level of their L2 grammatical proficiency.

2. to find out if the learner's grammatical proficiency in their L2 will influence their use of apology strategies.

\subsection{Methodology}

\subsubsection{Subjects}

40 students in the School of Foreign Languages in Yunnan Normal University were involved in the study. All the students are English majors. A grammar test adopted from Band 4 English proficiency Test for English major students in China was given to each student to test their grammatical competence. Then 40 students were divided into two groups with 20 students in each group according to their performance in the grammatical test. Group 1 is those with higher grammatical proficiency who scored higher in the test and Group 2 is those with lower grammatical proficiency who scored lower in the test. The division of the two groups is showed in table 2 and table 3 . There are 20 questions in the grammar test and 1 score for each question. The highest score of Group 1 is 18 and the lowest score is 11 . The highest score of Group 2 is 10 and the lowest score is 2 . The average score for Group 1 is 14.4 and the average score for Group 2 is 5.15 .

\subsubsection{Data collection}

A Discourse-Completion Test adopted from the Cross Culture Pragmatic Test of DCT of Hawaii university was given to both Group 1 and Group 2. The test contains three situations which all require students to complete the dialogue by eliciting an apology in each situation. These three situations are Situ.1,inconvenience offense (the apologizer fail to repair the watch for the regular customer on time), and Situ.3 time offense (keeping the president of the student organization waiting), which expect students to elicit explanations. Situ. 2 is possession offense (losing someone's book) which expects students to elicit an expression of responsibility or offer of repair. Each dialogue is preceded by a short description of the situation, setting and the social distance between the participant and their 
status relative to each other. In order to investigate the participants' ability in using combing strategies, all the situations are chosen to be the apologizer who has a lower status. Results were analyzed by the percentage of the frequency of the each apology strategy used.

\subsection{Findings}

\subsubsection{Use of (direct) explicit expression of an apology}

Table 4 shows the distribution of the direct explicit expression strategy used by both Group 1( the students with higher grammatical proficiency) and Group 2 (the students with lower grammatical proficiency) in all three situations.

Table 2. the use of explicit expression of apology (IFID) by both group in three situations

\begin{tabular}{|c|c|c|c|}
\hline & Situ.1 In small shop & Situ.2 Lose of book & Situ.3 Being late \\
\hline Group 1 & $85 \%$ & $80 \%$ & $100 \%$ \\
\hline Group 2 & $75 \%$ & $65 \%$ & $95 \%$ \\
\hline
\end{tabular}

The overall numbers indicate that both groups tend to choose IFIDs in all three situations to a similar degrees, yet there are some differences in specific cases. In situation 3, being late for the meeting, both groups have the highest preference for IFIDs, and in situation 2., losing someone's book, both groups have the lowest preference for IFIDs. However, as we can see in the table, Group 2 do have a lower preference for IFIDs than Group 1 in all three situations, though the difference is not very distinct.

\subsubsection{Use of an explanation}

Table 5 shows the frequency of the explanation strategy used in all three situations by Group1 and Group 2.

Table 3. the use of an explanation by both group in three situations

\begin{tabular}{|c|c|c|c|}
\hline & Situ.1 In small shop & Situ.2 Lose of book & Situ.3 Being late \\
\hline Group 1 & $85 \%$ & $100 \%$ & $95 \%$ \\
\hline Group 2 & $40 \%$ & $85 \%$ & $35 \%$ \\
\hline
\end{tabular}

As we can see in table 5, Group 1 showed a higher preference in using explanation than Group 2 did in all three situations. However, $85 \%$ of Group 1 used explanation in situation 1, while only $40 \%$ of Group 2 did, and $95 \%$ of Group 1 had explanation but only $35 \%$ of Group 2 did in situation 3 . 4.3.3 The use of acknowledgement of responsibility

Table 6 shows the frequency of the use of an acknowledgement of responsibility by both groups in all three situations.

Table 4. the use of responsibility by both group in three situations

\begin{tabular}{|c|c|c|c|}
\hline & Situ.1 In small shop & Situ.2 Lose of book & Situ.3 Being late \\
\hline Group 1 & $100 \%$ & $75 \%$ & $80 \%$ \\
\hline Group 2 & $80 \%$ & $20 \%$ & $20 \%$ \\
\hline
\end{tabular}

Similar to the use of IFID and explanation, Group 1 again showed a higher preference in the use of acknowledgement of responsibility. Difference between the two groups are distinct in situation 2 and situation $3.75 \%$ of Group 1 acknowledged responsibility and only $20 \%$ of Group 2 did in situation 2 , and there are more students in group $1(80 \%)$ than Group 2 students $(20 \%)$ did acknowledgement of responsibility in situation 3 .

\section{Discussion}


Findings of the use of an expression of an apology (IFIDs), an explanations and acknowledgement of responsibilities strategies in three situations shows that students' selections of apology strategies and semantic formulae varied with their grammatical competence.

As the results of the students' use of an expression of an apology showed, all the students in the study had a comparatively higher preference for choosing an expression of explicit apology. These findings conform in previous research that the IFID strategy is the most frequently used one[11]. However, the students of Group 1 were able to choose more semantic formulae such as "I am afraid I lost your book" or intensifiers as "I do apologize" to express an apology. The students with higher grammatical proficiency tended to be capable of choosing more strategies to intensify their degree of apology, while the students with lower grammatical proficiency had a comparatively narrow range of strategy choice. In all three situations, some students of Group 2 only used one strategy to perform an apology. This findings relates to Olstain's finding that students with low linguistic proficiency will lack the diversity in their use of semantic formulae [8].

By comparing the use of explanation by both groups, we can see that, most students of Group 1 could give a specific explanation in all three situations. For example, in situation 1 (inconvenience offense), explanations like " The watch is difficult to repair" or "I have been too busy these days" were provided by the students of Group 1. And in situation 3 (time offense), more explanation like "I met a traffic jam", "There was something wrong with my bicycle" and "My watch was slow" were given by Group 1 students to make the apology more effective. In situation 2 (possession offence), all the students in Group 1 gave an explanation, which including "I forgot where I put it", "I can not find your book" etc. While by looking at the results of Group 2, we can see that only $40 \%$ of Group 2 students gave an specific explanation in situation 1. Most of them just said to the customer something like "I can not do it today". Some of them used what the DCT provided in the situation description "It is not ready yet". There were $60 \%$ of the Group 2 students did not give any explanation for the delay of the service, which made their apology very impolite and not sincere. Situation 2 is a typical example for the use of combing an IFID with an explanation, though only $20 \%$ students from Group 2 provided the explanation. Among these explanations, some are very vague ones like "I have something to do" and "I met something on my way". 65\% of Group 2 student did not give any explanation and just said "I am sorry for being late", which was also impolite in this situation. These findings again support the argument that students with higher grammatical competence can choose more strategies and a richer variety of semantic formulae to elaborate their apology than students with lower grammatical proficiency.

The comparison of Group1 and Group2 students' use of an acknowledgement of responsibility in situation 1 showed that there was not much difference in their selection in situation 1 . Most of the students of both groups provided a certain form of repair. Though in situation 2 and 3, many differences exist. More students in Group 2 did not use the responsibility strategy. Through comparing their selection of different strategies in acknowledging responsibility for the offense in all three situations, we can see that besides using an offer of repair, Group 1 students used other strategies as accepting blame, an expressing self-deficiency more than Group 2 students did in all three situations. Group 2 students has a limited range of selection in using more strategies, and not using an acknowledgement of responsibility in situation 2 and 3 made Group 2 students' apologies inappropriate.

All these findings confirm Bardovi-Harlig's notion that higher levels of grammatical learner show a wide range of pragmatic competence[12]. Students Grammatical proficiency do have an influence on their performance for an apology.

\section{Conclusion}

The study reported here was an attempt to document variations in the strategies and semantic formulae of apology used by students with different levels of L2 grammatical proficiency. The analysis of the strategy types of an expression of an apology (IFIDs), an account of an explanation and an acknowledgement of responsibility by two groups of students with different L 2 grammatical 
proficiency indicates that students with higher grammatical proficiency are able to use more strategies and a richer variety of semantic formulae to elaborate their apology. Students with lower grammatical proficiency have a narrow range to choose apology strategies and the lack of the grammatical competence makes them be lack of the ability to use combining strategies to intensify their apology. The study shows that the students' level of grammatical proficiency does have an influence on their performance of an apology. There are also some limitations of the study. Since the data of the responses of each students were collected through written form and only three situations are provided, we can not be sure what they actually say in a real context, or how they will respond in much wider range of situation which requires an apology. Better means of collecting data should be developed in investigating other speech acts included in the Searle Category of expressive.

\section{Reference}

[1] D. Hymes, On communicative competence. In J.B. Pride \& J. Holmes (Eds) Sociolinguistics. Harmondswoth, Middlesex, England : Penguin,1972.

[2] M. Canale \& M.Swain, Theoretical bases of communicative approaches to second language teaching and testing, Applied linguistics, vol.1, pp. 1-47,1980.

[3] J. Thomas, Cross-Culture pragmatic failure. Applied Linguistics, vol.4, pp.91-112,1983.

[4] G.Yule, Pragmatics, In H.G. Widdowson (eds), Linguistics, Oxford University Press, 1996.

[5] L. Yates, "Ciao, guys!:" mitigation addressing positive and negative face concerns in the directive of native-speaker and Chinese background speakers of Australian English. PhD thesis, La Trobe University, pp. 79-85,2000.

[6] J. Searle, The classification of illocutionary acts, Language in Society, vol.5, pp.1-24,1976.

[7] E. Finegan, N. Besnier, D. Blair, \& P. Collins, Speech act and conversation, Language:Its Structure and Use, Marrickville, NSW: Harcourt Brace Janovich, pp.305-334,1992.

[8] E. Olshtain, Apologies across languages, In S. Blum-Kulka et. Al. (eds) Cross-cultural Pragmatics, Norwood, New York, Ablex , pp.155-173, 1989.

[9] S. Blum-Kulka, J. House, \& G. Kasper, Investigating cross-culture pragmatics: an introductory overview, In Blum_Kulka, S., House, J. \& Kasper, G. (eds), Cross-cultural pragmatics: requests and apologies . Norwood, New Jersey: Ablex Publishing Corporation, pp.1-36, 1989.

[10] E. Olshtain, \& A.Cohen, Apology: a speech act set. In N. Wolfson and E. Judd (Eds.) Sociolinguistics and Language Acquisition. Rowley, Mass, Newbury House pp.18-36,1983.

[11] J. Holmes, Apologies in New Zealand English, Language In Society, 19, pp.155-199, 1999.

[12] K. Bardovi-Harlig, Pragmatics and language teaching: Bringing pragmatics and pedagogy together, Pragmatics and Language learning, pp. 21-39, 1996. 